Page 2-6: Sample descriptions

Page 7-8: (U-Th)/He chronometry

Page 9-11: Measurement of stable oxygen isotopes in goethite

Page 12-14: Stable oxygen isotope measurements of large-mass samples

Page 15: (U-Th)/He age to paleolatitude transformations

Page 16: IAEA GNIP data

Page 17: References

Figure DR1: Hand sample photos

Figure DR2: Photomicrographs and SEM images

Figure DR3: IAEA GNIP site map

Table DR1: Sample location and brief description.

Table DR2: Chemical composition of samples

Table DR3: New (U-Th)/He ages

Table DR4: Complete $\delta^{18} \mathrm{O}$ results

Table DR5: $\delta^{18} \mathrm{O}$ Results of large mass Lynn Peak aliquots

Table DR6: Comparison between normal mass and large mass measurements

Table DR7: Conversion of (U-Th)/He ages to paleolatitudes

Table DR8: IAEA GNIP data 


\section{Samples Descriptions}

Iron oxide environments sampled for this study fall into three groups: (i) lateritic weathering profiles; (ii) ferruginized colluvia; and (iii) channel iron deposits.

Lateritic weathering profiles sit directly on top of iron rich rock, in the case of the Hamerlsey region, on top of a banded iron formation (BIF). A lateritic ferricrust grows downward as seasonal rainfall in combination with plant-derived organic acids triggers the dissolution of BIF minerals, leaving voids for subsequent goethite precipitation (Lascelles, 2012; Kneeshaw and Morris, 2014). This process produces a vitreous goethite cap often meters to tens of meters thick, with small fragments of remnant original hematite present (Kneeshaw and Morris, 2014). Our samples collected from Metawandy Valley represent typical lateritic weathering profile material developed on a BIF (Figure DR1a).

On the flanks of the BIF landforms, ferruginized colluvia encompass another ironrich environment in the Hamersley region. These deposits are dominated by hematite alluvium with preserved original BIF textures cemented by vitreous goethite (Kneeshaw and Morris, 2014). The Roy Hill samples in this study represent such ferruginized colluvia deposits (Figure DR1d).

Channel iron deposits are ferruginized paleochannels, primarily found in low valleys but also extending onto surrounding plains, dominated by pisoliths, ferruginized wood and goethite cement (Ramanaidou et al., 2003; Kneeshaw and Morris, 2014). The large stream channel size (10s of m wide), long length (sometimes hundreds of $\mathrm{km}$ ), gentle gradients, meandering form, and wide geographic occurrence indicate these were well-developed river systems during a time Western Australia had a more active 
hydraulic cycle than today (Ramanaidou et al., 2003). The Lynn Peak (Figure DR1c) and Yandi (Figure DR1b) samples in this study represent typical CID material.

Natural goethites produced by weathering reactions can range widely in physical and chemical properties, from a disseminated yellowy stain to dense, compact, pure, and highly crystalline masses. Only the latter material was selected for this work. A subset of the samples reported on here were previously characterized by optical microscopy, XRD, SEM, and electron microprobe analysis (Heim et al., 2006; Heim, 2007; Vasconcelos et al., 2013). In this subset, XRD and high-resolution synchrotron analyses yield sharp symmetrical peaks, suggesting a high degree of goethite crystallinity (Heim, 2007; Vasconcelos et al., 2013). Illustrative reflected light photomicrographs and SEM images are shown in Figure DR2. These results are typical of the samples analyzed here.

Goethite may contain variable abundances of $\mathrm{SiO}_{2}$ (possibly as a discrete phase), as well as substitution of $\mathrm{Al}$ for $\mathrm{Fe}$ within the mineral structure (Schwertmann, 1988). These impurities might affect either the He age or the oxygen isotope composition of our goethites. Table DR-2 reproduces previously published $\mathrm{Al}$ and $\mathrm{Si}$ data on a subset of samples analyzed in this study, including specimens from all four studied localities. Si spot analyses range from 0.10 - 2.93 wt \% (Heim, 2007; Vasconcelos et al., 2013), with the average Si content of individual samples ranging from $0.29 \mathrm{wt}$. $\%$ to $1.71 \mathrm{wt}$. $\%$ (Table DR2). Al spot analyses range from below detection to $5.90 \mathrm{wt}$ \%, with the average $\mathrm{Al}$ content of individual samples ranging from $0.01 \mathrm{wt}$. \% to $4.07 \mathrm{wt}$. \% (Table DR2). We observe no correlations between $\mathrm{Al}$ or $\mathrm{Si}$ content and He age or oxygen isotope composition within our data set. For example, while the Yandi samples have the most variable $\mathrm{Al}$ and $\mathrm{Si}$ content, they are not anomalous (nor anomalously variable) in $\delta^{18} \mathrm{O}$ or GHe age. 
Table DR1: Sample locations and brief descriptions

\begin{tabular}{lllll}
\hline \hline Sample & Northing & Easting & Host Rock & Depth \\
\hline Stop1-6-A1 & -22.747 & 116.612 & Lateritic ferricrust & Surface \\
Stop1-6-A7 & -22.747 & 116.612 & Lateritic ferricrust & Surface \\
Stop1-6-A5 & -22.747 & 116.612 & Lateritic ferricrust & Surface \\
Stop1-1-A3 & -22.747 & 116.612 & Lateritic ferricrust & Surface \\
Yan-02-09 & -22.721 & 119.080 & CID & Surface \\
Yan-02-02 & -22.721 & 119.080 & CID & Surface \\
Yan-02-01-A & -22.721 & 119.080 & CID & Surface \\
Yan-02-03 & -22.721 & 119.080 & CID & Surface \\
Yan-02-06 & -22.721 & 119.080 & CID & Surface \\
Yan-02-01-D1 & -22.721 & 119.080 & CID & Surface \\
LynP-02-09-A5 & -22.50 & -120.09 & CID & Surface \\
LynP-02-09-A3 & -22.50 & -120.09 & CID & Surface \\
LynP-02-09-A2 & -22.50 & -120.09 & CID & Surface \\
LynP-02-09-A1 & -22.50 & -120.09 & CID & Surface \\
Roy-02-02-Cy1 & -22.452 & 119.930 & Ferruginized colluvia & Surface \\
Roy-02-02-Cy2 & -22.452 & 119.930 & Ferruginized colluvia & Surface \\
Roy-02-02-Cy3 & -22.452 & 119.930 & Ferruginized colluvia & Surface \\
Roy-02-02-B5 & -22.452 & 119.930 & Ferruginized colluvia & Surface \\
Roy-02-02-Co3 & -22.452 & 119.930 & Ferruginized colluvia & Surface \\
Roy 02-02-C1 & -22.452 & 119.930 & Ferruginized colluvia & Surface \\
Roy-02-02-B1 & -22.452 & 119.930 & Ferruginized colluvia & Surface \\
\hline
\end{tabular}

Table DR2: Summary of electron microprobe analyses

\begin{tabular}{|c|c|c|c|c|c|c|c|}
\hline Sample & $\begin{array}{l}\text { Average Al } \\
\text { (wt. \%) }\end{array}$ & $\mathrm{n}$ & $\begin{array}{l}\text { Min Al } \\
\text { (wt. \%) }\end{array}$ & $\begin{array}{l}\text { Max Al } \\
(w t \%)\end{array}$ & $\begin{array}{l}\text { Average } \\
\text { Si (wt. \%) }\end{array}$ & $\begin{array}{l}\text { Min Si } \\
\text { (wt. \%) }\end{array}$ & $\begin{array}{l}\text { Max Si } \\
\text { (wt. \%) }\end{array}$ \\
\hline Stop-1-6-A1* & 0.01 & 9 & $\mathrm{BD}$ & 0.05 & 1.02 & 0.87 & 1.20 \\
\hline Stop-1-6-A5* & 0.11 & 4 & 0.09 & 0.14 & 1.71 & 1.67 & 1.79 \\
\hline Stop-1-6-A7* & 0.05 & 5 & 0.05 & 0.10 & 1.38 & 1.79 & 1.89 \\
\hline Yan-02-01-A* & 1.62 & 10 & 0.17 & 4.94 & 1.35 & 0.69 & 2.93 \\
\hline Yan-02-02* & 3.62 & 6 & 2.53 & 4.95 & 0.76 & 0.67 & 0.87 \\
\hline Yan-02-03* & 4.07 & 7 & 3.40 & 4.50 & 1.58 & 1.32 & 1.80 \\
\hline Yan-02-06* & 0.45 & 15 & 0.11 & 1.45 & 0.56 & 0.08 & 0.88 \\
\hline Yan-02-09* & 0.43 & 10 & 0.23 & 0.96 & 0.97 & 0.88 & 1.14 \\
\hline LynP-02-09-A1 ${ }^{\dagger}$ & 0.64 & 23 & 0.11 & 2.37 & 0.29 & 0.15 & 0.97 \\
\hline LynP-02-09-A2 ${ }^{\dagger}$ & 2.30 & 38 & 0.15 & 5.90 & 0.36 & 0.10 & 1.65 \\
\hline LynP-02-09-A3 ${ }^{+}$ & 1.08 & 20 & 0.26 & 3.24 & 0.42 & 0.13 & 2.79 \\
\hline Roy-02-02-B5* & 0.03 & 30 & 0.00 & 0.05 & 0.84 & 0.68 & 0.99 \\
\hline Roy-02-02-B1* & 0.02 & 30 & 0.00 & 0.03 & 0.86 & 0.69 & 0.95 \\
\hline
\end{tabular}

* (Heim, 2007); ${ }^{\dagger}$ (Vasconcelos, 2013) BD - below detection. $\mathrm{n}$ - number of points analyzed. 

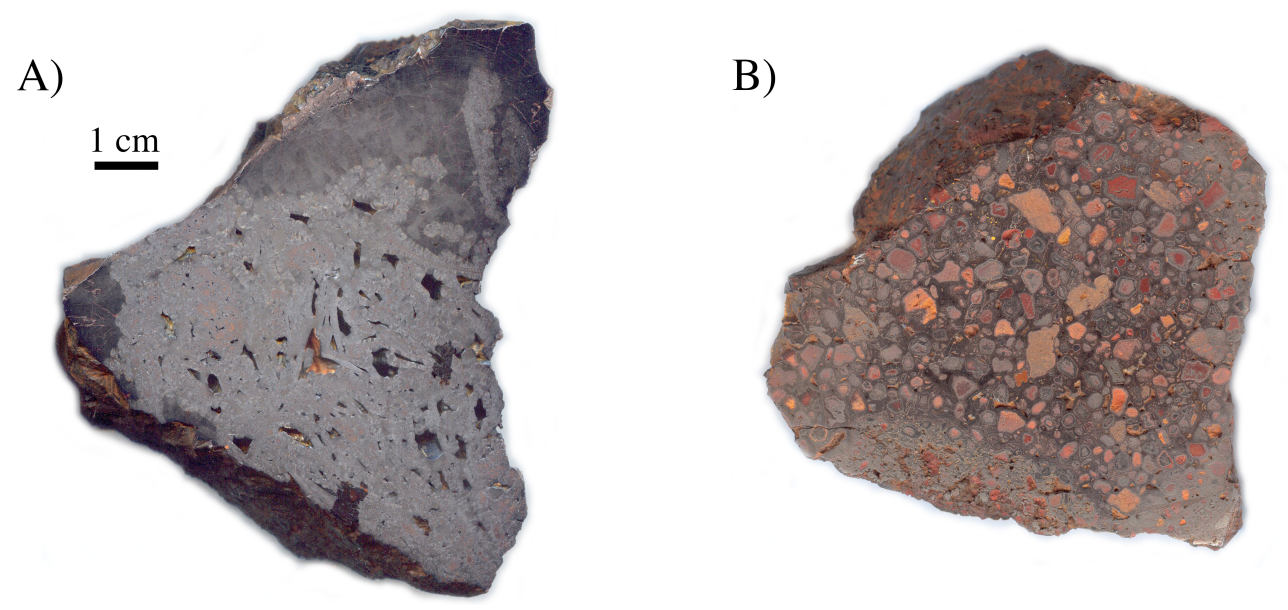

C)
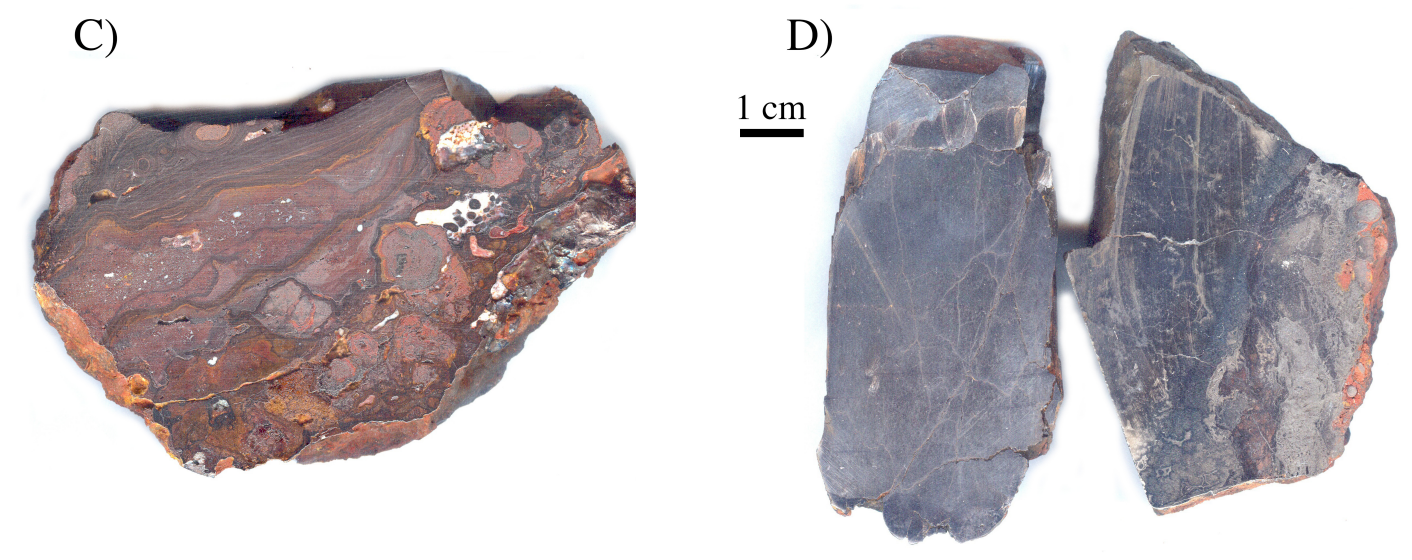

Figure DR1: Cut hand samples show characteristic textures of each locality from this study. (A) Botryoidal goethite crystals formed in cavities at Metawandy Valley; (B) pisolith and detrital hematite clasts supported in a goethite matrix at Yandi and (C) Lynn Peak; (D) elongate fibrous crystals of Roy Hill. 


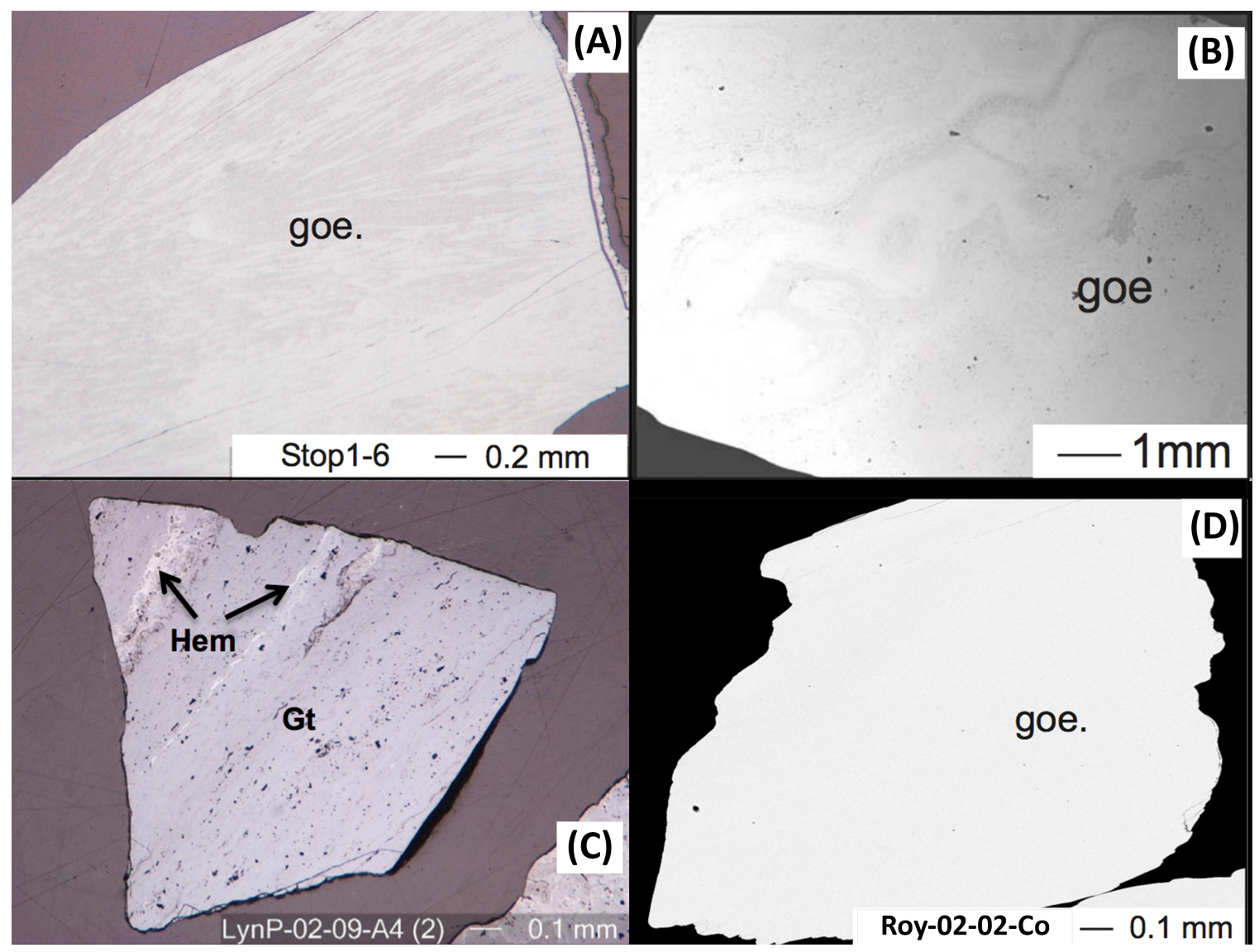

Figure DR2: (A) Representative reflected light photomicrograph of Metawandy Valley sample Stop-1-6, with fibrous crystal growth habit visible. (B) SEM image showing Yandi CID goethite, the darker zones represent greater Al substitution. See Table DR2 for measurements of Al concentration. (C) Reflected light photomicrograph of LynP-02-09-A4, showing the presence of both hematite (Hem) and goethite (Gt). Mixed mineralogy samples such as this one were not analyzed for (U-Th)/He ages or oxygen isotope composition. (D) A SEM image of Roy Hill sample Roy02-02-Co showing our preferred material for geochronology and oxygen isotope analysis: this goethite has uniform composition and low abundance of $\mathrm{Al}$ and $\mathrm{Si}$ (see Table DR2). 


\section{(U-Th)/He chronometry}

GHe ages were determined following the procedures of Shuster et al. (2005) and Vasconcelos et al. (2013). Two to three 0.1 to $3 \mathrm{~mm}$ fragments ( $\sim 100 \mathrm{ug})$ were selected for coarse, crystalline texture, then individually packaged in Pt tubes, heated by laser, and ${ }^{4} \mathrm{He}$ concentrations measured by quadrupole mass spectrometer following cryogenic separation of $\mathrm{He}$ and the addition of ${ }^{3} \mathrm{He}$ spike. After complete degassing, the goethite grains within Pt tubes were transferred to a Teflon beaker containing ${ }^{230} \mathrm{Th}$ and ${ }^{235} \mathrm{U}$ spikes and dissolved in concentrated $\mathrm{HCl}$ by heating for 12 hours to $90^{\circ} \mathrm{C}$. The spiked solutions were diluted and $\mathrm{U}$ and $\mathrm{Th}$ concentrations analyzed by quadrupole inductively coupled plasma-mass spectrometry (ICP-MS).

All samples were dated in duplicate or triplicate, and mean GHe ages are reported. The analytical uncertainty of $\pm 2 \%$ underestimates the true uncertainty on formation age because most goethites lose at least a few $\%$ of their ${ }^{4} \mathrm{He}$ under earth surface conditions (Shuster et al., 2005). For example, ${ }^{4} \mathrm{He} /{ }^{\beta} \mathrm{He}$ experiments on Lynn Peak goethites show that these samples experienced $\sim 5 \%$ He loss (Vasconcelos et al., 2013). In the absence of ${ }^{4} \mathrm{He} /{ }^{3} \mathrm{He}$ experiments on all of our samples, we make an approximate correction for this effect by assuming $10 \% \mathrm{He}$ loss and conservatively assign a $\pm 10 \%$ uncertainty to all He ages (e.g., as in Monteiro et al., 2014). 
Table DR3: New (U-Th)/He results

\begin{tabular}{|c|c|c|c|c|c|c|}
\hline & $\begin{array}{l}\text { Corrected } \\
\text { Age (Ma) }\end{array}$ & \pm & $\mathrm{U}(\mathrm{ppm})$ & Th (ppm) & $\begin{array}{l}\mathrm{He} \\
(\mathrm{nmol} / \mathrm{g})\end{array}$ & Mass $(\mu \mathrm{g})$ \\
\hline Stop1-6-A1-A & 4.5 & 0.5 & 5.62 & 0.16 & 0.13 & 72 \\
\hline Stop1-6-A1-B & 5.6 & 0.6 & 5.15 & 0.09 & 0.14 & 49 \\
\hline Stop1-6-A1-C & 4.4 & 0.4 & 5.54 & 0.15 & 0.12 & 64 \\
\hline Mean & 4.8 & & 5.4 & 0.1 & 0.1 & \\
\hline Stop1-6-A7-A & 4.9 & 0.5 & 4.46 & 0.12 & 0.11 & 35 \\
\hline Stop1-6-A7-B & 4.9 & 0.5 & 4.55 & 0.03 & 0.11 & 41 \\
\hline Mean & 4.9 & & 4.5 & 0.1 & 0.1 & \\
\hline Stop1-6-A5-A & 7.5 & 0.8 & 5.23 & 0.11 & 0.20 & 19 \\
\hline Stop1-6-A5-B & 9.6 & 1.0 & 4.94 & 0.07 & 0.24 & 32 \\
\hline Mean & 8.5 & & 5.1 & 0.1 & 0.2 & \\
\hline Stop1-1-A3-A & 25.8 & 2.6 & 2.86 & 0.04 & 0.37 & 67 \\
\hline Stop1-1-A3-B & 26.2 & 2.6 & 2.79 & 0.08 & 0.37 & 64 \\
\hline Mean & 26.0 & & 2.8 & 0.1 & 0.4 & \\
\hline Roy-02-02-Cy1-A & 44.3 & 4.4 & 1.36 & 1.26 & 0.36 & 48 \\
\hline Roy-02-02-Cy1-B & 48.3 & 4.8 & 1.28 & 1.27 & 0.38 & 53 \\
\hline Roy-02-02-Cy1-C & 49.3 & 4.9 & 1.15 & 0.40 & 0.30 & 59 \\
\hline Mean & 47.3 & & 1.3 & 1.0 & 0.3 & \\
\hline Roy-02-02-Сy2-A & 65.6 & 6.6 & 0.69 & 0.17 & 0.24 & 48 \\
\hline Roy-02-02-Сy2-B & 60.8 & 6.1 & 0.75 & 0.26 & 0.25 & 35 \\
\hline Roy-02-02-Cy2-C & 58.6 & 5.9 & 0.98 & 0.32 & 0.31 & 78 \\
\hline Mean & 61.7 & & 0.8 & 0.3 & 0.3 & \\
\hline Roy-02-02-Сy3-A & 66.9 & 6.7 & 1.16 & 0.32 & 0.41 & 73 \\
\hline Roy-02-02-Сy3-B & 61.1 & 6.1 & 1.55 & 0.21 & 0.49 & 69 \\
\hline Roy-02-02-Сy3-C & 76.0 & 7.6 & 1.13 & 0.35 & 0.46 & 78 \\
\hline Mean & 68.0 & & 1.3 & 0.3 & 0.5 & \\
\hline Roy-02-02-B5-A & 69.3 & 6.9 & 1.38 & 0.09 & 0.48 & 64 \\
\hline Roy-02-02-B5-B & 66.7 & 6.7 & 1.18 & 0.08 & 0.40 & 58 \\
\hline Mean & 68.0 & & 1.3 & 0.1 & 0.4 & \\
\hline Roy-02-02-C1-A & 70.5 & 7.1 & 1.19 & 0.04 & 0.42 & 63 \\
\hline Roy-02-02-C1-B & 71.2 & 7.1 & 1.18 & 0.07 & 0.42 & 58 \\
\hline Roy-02-02-C1-C & 69.8 & 7.0 & 1.22 & 0.05 & 0.43 & 51 \\
\hline Mean & 70.5 & & 1.2 & 0.1 & 0.4 & \\
\hline Roy-02-02-Co3-A & 72.3 & 7.2 & 1.25 & 0.09 & 0.46 & 60 \\
\hline Roy-02-02-Co3-B & 62.9 & 6.3 & 1.43 & 0.17 & 0.46 & 44 \\
\hline Roy-02-02-Co3-C & 71.2 & 7.1 & 1.33 & 0.11 & 0.48 & 94 \\
\hline Mean & 68.8 & & 1.3 & 0.1 & 0.5 & \\
\hline
\end{tabular}




\section{Measurement of stable oxygen isotopes in goethite}

Using the sample material recovered from the same initial $4 \mathrm{~mm}$ drill core that geochronometry aliquots were selected from, $10 \mathrm{mg}$ of goethite was crushed to $100-300$ micron size, sieved, and ultrasonically cleaned in ethanol. A $\sim 2 \mathrm{mg}$ aliquot of sample was heated to $80^{\circ} \mathrm{C}$ under vacuum overnight and then pretreated with $\mathrm{BrF}_{5}$ vapor at room temperature to remove any remaining adsorbed water. The sample was then irradiated with a $10.6 \mu \mathrm{CO}_{2}$ laser while exposed to $\mathrm{BrF}_{5}$ vapor, driving fluorination reactions that produce $\mathrm{O}_{2}, \mathrm{HF}$ and iron fluoride. The $\mathrm{O}_{2}$ was isolated and purified by cryogenic separation and passage over hot mercury, then converted to $\mathrm{CO}_{2}$ by passage over hot graphite and analyzed by dual inlet gas source mass spectrometry in that form (Sharp et al., 1990). A garnet standard, UWG-2, was measured throughout each analytical session to monitor the accuracy of each session's measurements. When the measured $\delta^{18} \mathrm{O}$ of UWG-2 varied from the known value, a correction was applied, typically $\sim 0.10 \%$ o (Valley et al., 1995). The final pressure of $\mathrm{CO}_{2}$ produced from a sample fluorination reaction and subsequent $\mathrm{CO}_{2}$ conversion was measured and used to check that a sample was completely fluorinated, as partial sample fluorination may induce isotopic fractionation (Valley et al., 1995). Analyses were discarded ( 25\% of total analyses made) when the measured moles of $\mathrm{CO}_{2}$ differed from the mass-based prediction by more than $10 \%$. In the case of samples with published (U-Th)/He ages, the material prepared for $\delta^{18} \mathrm{O}_{\mathrm{goe}}$ was sourced from remaining crushate produced from texturally uniform bands within the $4 \mathrm{~mm}$ cores used for the original (U-Th)/He analyses. 
Table DR4: All Laser Fluorination $\delta^{18} \mathrm{O}$ results

\begin{tabular}{|c|c|c|c|}
\hline Sample & Subsample & $\overline{\delta^{18} \mathrm{O}_{\text {VSMOW }}(\%)}$ & \pm \\
\hline Stop1-6-A5 & & -0.370 & 0.024 \\
\hline Stop1-6-A1 & & -0.316 & 0.015 \\
\hline \multirow[t]{3}{*}{ Stop1-6-A7 } & & -0.207 & 0.033 \\
\hline & & -0.228 & 0.028 \\
\hline & & -0.107 & 0.041 \\
\hline Mean & & -0.181 & \\
\hline \multirow[t]{4}{*}{ Stop1-1-A3 } & & -1.257 & 0.035 \\
\hline & & -1.176 & 0.014 \\
\hline & & -0.888 & 0.027 \\
\hline & & -0.873 & 0.022 \\
\hline Mean & & -1.049 & \\
\hline Yan-02-01-A & & 0.677 & 0.026 \\
\hline Yan-02-01-D1 & & 0.727 & 0.055 \\
\hline Yan-02-02 & & 0.703 & 0.022 \\
\hline Yan-02-03 & & 0.976 & 0.028 \\
\hline Yan-02-09 & & 0.627 & 0.027 \\
\hline Yan-02-06 & & -0.088 & 0.028 \\
\hline \multirow[t]{7}{*}{ LynP-02-09-A1 } & A & -0.945 & 0.016 \\
\hline & A & -0.977 & 0.022 \\
\hline & B & 0.324 & 0.019 \\
\hline & B & 0.188 & 0.047 \\
\hline & B & -0.069 & 0.028 \\
\hline & $\mathrm{C}$ & -0.872 & 0.030 \\
\hline & $\mathrm{D}$ & -1.002 & 0.034 \\
\hline Mean & & -0.479 & \\
\hline \multirow[t]{2}{*}{ LynP-02-09-A2 } & & -0.714 & 0.027 \\
\hline & & -0.576 & 0.045 \\
\hline Mean & & -0.645 & \\
\hline
\end{tabular}


Table DR4: All Laser Fluorination $\delta^{18} \mathbf{O}_{\text {vsmow }}$ results (continued)

\begin{tabular}{|c|c|c|c|}
\hline Sample & Subsample & $\bar{c}^{18} \mathrm{O}_{\text {VSMOW }}(\% 0)$ & \pm \\
\hline \multirow[t]{6}{*}{ LynP-02-09-A3 } & A & 0.569 & 0.037 \\
\hline & $\mathrm{A}$ & 0.522 & 0.033 \\
\hline & $\mathrm{B}$ & -0.509 & 0.024 \\
\hline & B & -0.920 & 0.029 \\
\hline & $\mathrm{C}$ & -0.500 & 0.029 \\
\hline & $\mathrm{C}$ & -0.390 & 0.027 \\
\hline Mean & & -0.205 & \\
\hline \multirow[t]{2}{*}{ LynP-02-09-A5 } & & 0.613 & 0.038 \\
\hline & & 0.543 & 0.034 \\
\hline Mean & & 0.578 & \\
\hline \multirow[t]{4}{*}{ Roy-02-02-Cy 1} & & -1.855 & 0.030 \\
\hline & & -1.387 & 0.048 \\
\hline & & -1.231 & 0.060 \\
\hline & & -1.434 & 0.040 \\
\hline Mean & & -1.477 & \\
\hline \multirow[t]{2}{*}{ Roy $02-02-\mathrm{C} 1$} & & -1.037 & 0.039 \\
\hline & & -1.189 & 0.040 \\
\hline Mean & & -1.113 & \\
\hline \multirow[t]{2}{*}{ Roy-02-02-Co3 } & & -1.629 & 0.023 \\
\hline & & -1.631 & 0.030 \\
\hline Mean & & -1.630 & \\
\hline \multirow[t]{2}{*}{ Roy-02-02-Cy2 } & & -1.533 & 0.046 \\
\hline & & -1.685 & 0.046 \\
\hline Mean & & -1.609 & \\
\hline \multirow[t]{2}{*}{ Roy-02-02-Сy3 } & & -1.654 & 0.034 \\
\hline & & -1.710 & 0.025 \\
\hline Mean & & -1.682 & \\
\hline Roy-02-02-B5 & & -1.283 & 0.035 \\
\hline Roy-02-02-B1 & & -1.928 & 0.020 \\
\hline
\end{tabular}




\section{Stable oxygen isotope measurements of large-mass samples}

We found unexpectedly large $\delta^{18} \mathrm{O}$ variability in some of our samples. The reproducibility of UWG-2 standards, the mineralogical purity of goethite in this study (Heim et al., 2006; Heim, 2007; Vasconcelos et al., 2013), and the reproducible $\delta^{18} \mathrm{O}$ results from the remainder of our samples together suggest this variability is not inherent to the fluorination procedure or other aspects of the analytical method. As an alternative, we hypothesize that some of our samples contain isotopic heterogeneity arising from factors occurring on short timescales and therefore over small length scales of goethite growth. If so, we expect that replicate measurements of small samples $(2 \mathrm{mg})$ will yield the same mean as analysis of a much larger sample mass. To test this hypothesis, we measured the $\delta^{18} \mathrm{O}$ of two of the anomalously variable goethite samples with five times more than our typical sample mass. Weighed samples and standards are typically loaded into a nickel disc with 36 pits. For this experiment, we loaded five adjacent pits each with the $\sim 2 \mathrm{mg}$ sample mass typical of laser fluorination measurements, then drew a proportionally larger quantity of $\mathrm{BrF}_{5}$ to completely fluorinate the larger mass sample, and lased them all. Typical pretreatment, fluorinated species purification, and $\mathrm{CO}_{2}$ conversion were all followed for these large-mass measurements. We allowed for a lower yield criterion in these large-mass measurements due to very slow conversion to $\mathrm{CO}_{2}$. We suspect that the graphite rod reaches a saturation state when exposed to gas from these large mass fluorination reactions and incompletely converted our sample to $\mathrm{CO}_{2}$. Larger aliquots produced $\delta^{18} \mathrm{O}_{\text {goe }}$ results consistent with the average of the smaller aliquots. Thus we interpret these observations to indicate that in some of our samples, $2 \mathrm{mg}$ aliquots were too small to capture the average composition of the goethite. This fine scale heterogeneity may be due to local variations in meteoric 
water on time scales unresolvable by GHe dating. By averaging the $\delta^{18} \mathrm{O}$ of the smaller aliquots, we obtain our best estimate of the composition of the goethite at the time associated with the GHe age. 
Table DR5: Large mass $\delta^{18}$ Vvgow $_{\text {measurements }}$

\begin{tabular}{lllll}
\hline \hline Aliquot & Yield (\%) & Mass $(\mathrm{mg})$ & $\delta^{18} \mathrm{O}_{\mathrm{VSMOW}}(\%)$ & \pm \\
\hline LynP-02-09-A1 (1A) & 82.7 & 10.72 & -0.615 & 0.018 \\
LynP-02-09-A1 (1B) & 89.8 & 6.96 & 0.024 & 0.038 \\
LynP-02-09-A3 (1A) & 80.4 & 11.04 & 0.270 & 0.019 \\
LynP-02-09-A3 (1B) & 81.3 & 7.52 & 0.031 & 0.015
\end{tabular}

Table DR6: Comparison between normal mass and large mass measurements

A) LynP-02-09-A1

Normal Mass Aliquots

Number

7

Average $\delta^{18} \mathrm{O}(\% \mathrm{o})$

$-0.479$

Total mass analyzed (mg)

10.78

$\delta^{18} \mathrm{O}(\%)$ High Value

0.324

$\delta^{18} \mathrm{O}(\%)$ Low Value

$-1.002$

Range $\delta^{18} \mathrm{O}(\%)$

1.326

Large Mass Aliquots

Number 2

(Mass weighted) Average $\delta^{18} \mathrm{O}(\%)$

$-0.363$

Total mass analyzed (mg)

17.68

Difference between average of normal mass and large mass $\delta^{18} \mathrm{O}(\%)$

0.116

B) LynP-02-09-A3

Normal Mass Aliquots

Number 6

Average $\delta^{18} \mathrm{O}(\%)$

$-0.205$

Total mass analyzed (mg)

9.02

$\delta^{18} \mathrm{O}(\%)$ High Value

0.569

$\delta^{18} \mathrm{O}(\%)$ Low Value

$-0.920$

Range $\delta^{18} \mathrm{O}(\%)$

1.489

Large Mass Aliquots

Number

(Mass weighted) Average $\delta^{18} \mathrm{O}(\%)$

Total mass analyzed (mg)

Difference between average of normal mass and large mass $\delta^{18} O(\%)$

\section{2}

0.173

18.56

0.378 


\section{(U-Th)/He age to paleolatitude transformations}

(U-Th)/He ages were transformed to paleolatitude for each sample to explore the possible correlation between the modern latitudinal gradient in isotopic composition of meteoric water and our $\delta^{18} \mathrm{O}_{\text {goe }}$ record. Absolute plate speed and direction calculated by Muller et al. (2016) for the Australian plate from 80 Ma to present was used to determine paleolatitudes. The vector along which the center of the Australian plate traveled shifted from NW to NE with a speed of 1-3 cm/yr between $80 \mathrm{Ma}$ and $40 \mathrm{Ma}$ then increased speed significantly to between 6 and $8 \mathrm{~cm} / \mathrm{yr}$ in the NNE direction between $40 \mathrm{Ma}$ and present (Muller et al., 2016). Table DR7 presents the speed and direction of the Australian plate in $10 \mathrm{Ma}$ periods used to transform (U-Th)/He ages into paleolatitudes. Here we assume the $\pm 10 \%$ uncertainty applied to the (U-Th)/He ages dominates over the error associated with determining finite plate rotations and therefore the error assigned to sample paleolatitude is the result of propagating (U-Th)/He error through the latitude transformation. For Cenozoic plate reconstructions, where an absolute reference frame can be tied down via well-constrained subduction and hotspot locations, this assumption is likely valid (Muller et al., 2016).

\section{Table DR7: (U-Th)/He age to paleolatitude conversion rates}

\begin{tabular}{llll}
\hline \hline Age Range (Ma) & $\begin{array}{l}\text { Centimeters } \\
\text { per year }\end{array}$ & $\begin{array}{l}\text { Plate direction } \\
\text { (azimuth degrees) }\end{array}$ & $\begin{array}{l}\text { Kilometers north } \\
\text { per 10 Ma }\end{array}$ \\
\hline $0-10$ & 7.5 & 15 & 724.4 \\
$10-20$ & 7 & 15 & 676.1 \\
$20-30$ & 8 & 15 & 772.7 \\
$30-40$ & 6 & 20 & 563.8 \\
$40-50$ & 3 & 30 & 259.8 \\
$50-60$ & 3 & 50 & 192.8 \\
$60-75$ & 1 & -60 & 50.0
\end{tabular}


Table DR8: Compiled IAEA meteoric water data from South Pacific

\begin{tabular}{|c|c|c|c|}
\hline Latitude & $\begin{array}{l}\text { Long-term Mean* } \\
\delta^{18} \mathrm{O}_{\text {vSMow }}(\% \circ) \\
\end{array}$ & Standard Deviation & GNIP code \\
\hline-21.23 & -3.77 & 0.67 & 9184300 \\
\hline-23.70 & -2.90 & 1.72 & 9432600 \\
\hline-27.47 & -3.49 & 0.89 & 9457600 \\
\hline-31.94 & -3.11 & 0.34 & 9460800 \\
\hline-31.99 & -3.74 & 0.47 & 9460801 \\
\hline-34.93 & -4.01 & 0.47 & 9467500 \\
\hline-35.12 & -4.50 & 0.39 & 9301100 \\
\hline-37.81 & -4.63 & 0.63 & 9486800 \\
\hline-40.68 & -3.59 & 0.6 & 9495400 \\
\hline-43.02 & -5.04 & 1.31 & 9497001 \\
\hline-46.43 & -6.89 & 0.41 & 9384400 \\
\hline
\end{tabular}

The Global Network of Isotopes in Precipitation (GNIP) is part of the International Atomic Energy Agency's (IAEA) efforts to monitor the distribution and transportation of rare isotopes across our planet. Long-term mean refers to the mean of the annual mean rainwater $\delta^{18} \mathrm{O}$ over the lifespan of the collection site, which range between 6 and 54 years.

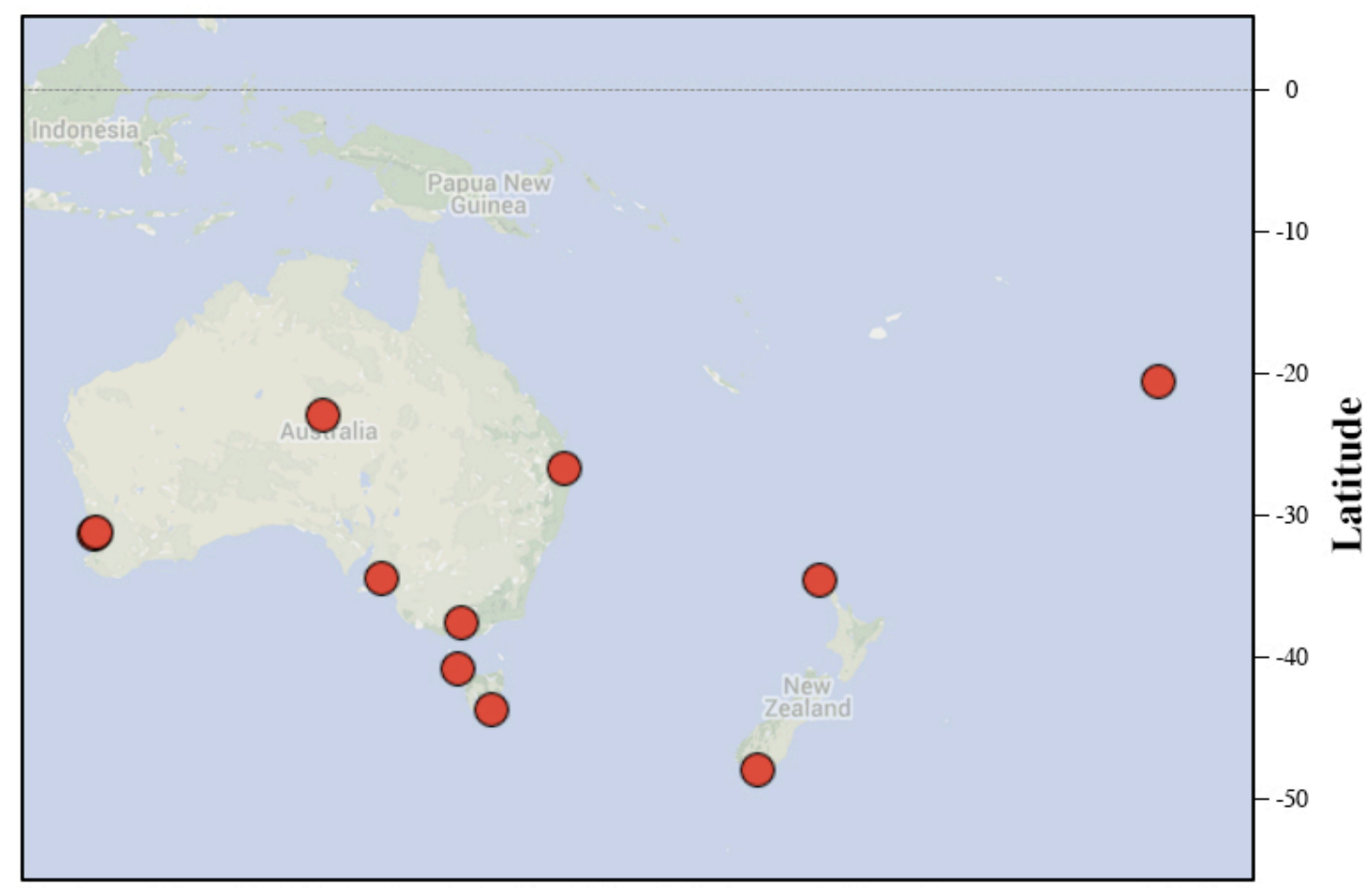

Figure DR3: Red circles show locations of IAEA GNIP collection sites used in this study to create a regional latitudinal gradient in the isotopic composition of rainwater. 


\section{References}

Heim, Jonathan Andrew (2007). Geochronology of weathering and landscape evolution, Hamersley Iron Province, Australia PhD Thesis, School of Physical Sciences, University of Queensland.

Heim, J.A., Vasconcelos, P.M., Shuster, D.L., Farley, K.A., and Broadbent, G., 2006, Dating paleochannel iron ore by (U-Th)/He analysis of supergene goethite, Hamersley province, Australia: Geology, v. 34, no. 3, p. 173.

Kneeshaw, M., and Morris, R.C., 2014, The Cenozoic detrital iron deposits of the Hamersley Province, Western Australia: Australian Journal of Earth Sciences, v. 61, no. 4 , p. 513-586.

Lascelles, D.F., 2012, Banded iron formation to high-grade iron ore: a critical review of supergene enrichment models: Australian Journal of Earth Sciences, v. 59, no. 8, p. 1105-1125.

Müller, R.D., Seton, M., and Zahirovic, S., 2016, Ocean basin evolution and global-scale plate reorganization events since Pangea breakup: Annual Review of Earth and Planetary Science, v. 44, p 107-138.

Ramanaidou, E.R., Morris, R.C., and Horwitz, R.C., 2003, Channel iron deposits of the Hamersley Province, Western Australia: Australian Journal of Earth Sciences, v. 50, no. 5, p. 669-690.

Sharp, Z. D., 1990, A laser-based microanalytical method for the in-situ determination of oxygen isotope ratios of silicates and oxides: Geochimica et Cosmochimica Acta, v. 54, p. 1353-1357.

Shuster, D. L., Vasconcelos, P. M., Heim, J. A., \& Farley, K. A., 2005, Weathering geochronology by (U-Th)/He dating of goethite: Geochimica Et Cosmochimica Acta, v. 69, p. 659-673.

Schwertmann U. 1988. Occurrence and forma- tion of iron oxides in various pedoenvironments, in Iron in Soils and Clay Minerals, v217, pp. 267-308

Valley, J. W., Kitchen, N., Kohn, M. J., Niendorf, C. R., \& Spicuzza, M. J., 1995. UWG2, a garnet standard for oxygen isotope ratios: strategies for high precision and accuracy with laser heating: Geochimica et Cosmochimica Acta, v. 59, p. 52235231.

Vasconcelos, P. M., Heim, J. A., Farley, K. A., Monteiro, H., \& Waltenberg, K., 2013, 40Ar/39Ar and (U-Th)/He - 4He/3He geochronology of landscape evolution and channel iron deposit genesis at Lynn Peak, Western Australia: Geochimica Et Cosmochimica Acta, v. 117, p. 283-312.

Wessel, P., and Müller, R.D., 2015, Plate Tectonics, in Treatise on Geophysics, 2nd edition, Schubert, Gerald ed., vol. 6, pp. 45-93. 